\title{
In situ Evolved Gas Analysis of TMOS-based Gel Electrolytes Containing Guanidinium Thiocyanate for Quasi-solid-state Dye-sensitized Solar Cells by TG-FTIR and TG-MS
}

\author{
Viola Nagygyörgy ${ }^{1 *}$, Elias Stathatos², György Pokol1,3, János Madarász \\ 1 Department of Inorganic and Analytical Chemistry, Faculty of Chemical Technology and Biotechnology, \\ Budapest University of Technology and Economics, HU-1111 Budapest, Szt. Gellért tér 4, Hungary \\ 2 Nanotechnology and Advanced Materials Laboratory, Technological-Educational Institute of Western Greece, \\ 26334 Patras, Greece \\ ${ }^{3}$ Research Centre for Natural Sciences, Hungarian Academy of Sciences, HU-1117 Budapest, Magyar tudósok körútja 2, Hungary \\ * Corresponding author, e-mail: nagygyorgy.viola@mail.bme.hu
}

Received: 09 July 2018, Accepted: 26 September 2018, Published online: 05 November 2018

\begin{abstract}
A comparative study on thermal stability of hybrid (organic/inorganic) electrolytes for dye-sensitized solar cells (DSSCs) in various ethylene oxide oligomers/silica based gelly matrices, containing also some efficiency-promoter additives is presented. Using thermogravimetry combined with two evolved gas analytical (EGA-FTIR and EGA-MS) techniques, the released gases and volatile decomposition products from the composite electrolytes during dynamic heating programs have been identified and monitored. First methanol (arising from condensation of tetramethoxysilane, TMOS) and acetonitrile (solvent) are evolved followed by elongated release of 4-tert-butylpyridine, than carbonyl sulfide, which is one of the degradation products of guanidinium thiocyanate, and various alkyl iodides, as well as iodine, later various oxidized species with $>\mathrm{C}=\mathrm{O}$ groups (arising from oxidative degradation of oligo(ethylene glycolic) parts, ammonia (originated from guanidine) have been observed and traced during the accelerated heating tests, before final burning out of the organic residue with $\mathrm{CO}_{2}$ evolution. Thermal behavior of pure guanidinium thiocyanate, one of the most important additives improving thermal stability of Grätzel type solar cells (DSSCs), combined with identification of its eight gaseous decomposition products and their release pattern is also reported.
\end{abstract}

\section{Keywords}

Grätzel type, dye-sensitized solar cell (DSSC), coupled evolved gas analysis (EGA), guanidinium thiocyanate, tetramethoxysilane (TMOS), thermogravimetry (TG), Triton X-100, PEG 200, Q-MS, FTIR-spectroscopic gas cell

\section{Introduction}

The family of dye-sensitized solar cells (DSSCs) is one of the most promising low cost alternative for the effective conversion of light energy into electrical energy [1].

The components of a DSSC are in most cases the following: a nanocrystalline $\mathrm{TiO}_{2}$ film deposited on a transparent conductive electrode, a complex ruthenium-dye adsorbed on $\mathrm{TiO}_{2}$ nanocrystallites, an electrolyte bearing the $\mathrm{I}^{-} / \mathrm{I}_{3}{ }^{-}$or other redox couple and a platinized counter electrode [2-5]. There are some concerns about the long term stability of such devices due to accidental leakage of the electrolyte as well as poor stability and durability of liquid electrolytes. In order to overcome these problems several alternatives have been proposed to replace liquid electrolytes with more solid ones [6-9].
One of the suggested alternative solutions to obtain a more solid state electrolyte is to introduce gelifiers into the electrolyte, thus making so-called quasi-solid-state DSSCs [10-12]. These quasi-solid cells have only slightly lower efficiency than liquid cells, mainly due to lower ionic conductivity, but their efficiency is still satisfying and the stability of the cells is improved. One of the ways to make gel electrolyte, which also the subject of the present work, is to produce a silica-based sol-gel containing an $\mathrm{I}^{-} / \mathrm{I}_{3}^{-}$redox couple [13]. The advantages of these sol-gel electrolytes are the following: these cells are practically solid devices, the silica backbones do not prevent electrical conduction, and the sol itself acting as a glue between the two electrodes, what facilitates the cell fabrication, 
meanwhile the ionic conductivity is ensured by the redox components dissolved in an highly polar organic liquid subphase of the gel [14]. E.g. polyethylene oxides have been found one of the most efficient subphase for this purpose [15], or they can be replaced by a combination of urea cross-linked polyether-siloxane hybrid materials (ureasils) [16], which we used as gelator in our previous work [17-19]. If polyether chains are covalently connected to silicon atoms originating from e.g. TMOS (tetramethoxysilane), the use of these polyether spacers is improving the diffusion of ions of the $\mathrm{I}^{-} / \mathrm{I}_{3}^{-}$redox couple, especially by coordinating the lithium ion of the electrolyte, improving the $\mathrm{I}^{-}$conductivity what can improve the cell efficiency [20, 21].

To further improve the performance of the DSSC, several kinds of additives can be added to the system, such as ionic liquids, (e.g. MPII, 1-methyl-3-propylimidazolium iodide), less volatile polar solvents (e.g. 3-methoxy-propionitrile), 4-tertbutylpiridine and guanidinium thiocyanate (GuSCN) [22-24]. The effect of GuSCN on the photovoltaic performance of the DSSC was first reported by Grätzel and co-workers [22, 25], and it seems to improve the photocurrent density values of solar cell, especially in case of co-adsorption with dyes [22] and has a very important role improving the thermal stability of the DSSC cell by minimizing the efficiency loss during thermal aging [26, 27].

The results of thermal aging studies show that the efficiency loss mostly depends on the composition of the electrolyte, the particular dye and the fabrication procedure [27]. In this work, we present comparative studies concerning thermal stability of hybrid electrolytes based on various polyethylene oxide oligomers / silica mixtures and also a thermal behavior study of the guanidinium thiocyanate, one of the most important additives improving cell efficiency and thermal stability by inhibiting thiocyanate ligand exchange of the dye what would cause degradation $[24,26,27]$. Thermogravimetry combined with gas analytical (MS and FTIR spectroscopic) techniques are performed to evaluate the escape / release tendency of volatile solvents, additives components leaving from the quasi solid electrolytes' matrices, as well as from pure guanidinium thiocyanate additive on various degradation pathways.

\section{Experimental}

\subsection{Components and Materials (Scheme 1)}

Lithium iodide (LiI, $98 \%$ ), iodine ( $\mathrm{I}_{2}$, reagent grade), 1-methyl-3-propylimidazolium iodide (MPII, $98 \%$ ), guanidinium thiocyanate (Gu-SCN, $97 \%$ ), 4-tert-butylpyridine (TBP, $96 \%$ ), tetramethoxysilane (TMOS, $99 \%$ ), poly(ethylene glycol) 200 (PEG 200) and all solvents were purchased from Sigma-Aldrich and used as received. Triton X-100 (4-(1,1,3,3-tetramethylbutyl)phenyl-polyethylene glycol) surfactant (99.8\%, Fisher Scientific), N719 (di-tetrabutylammonium cis-bis(isothiocyanato) bis(2,2'-bipyridyl-4,4'-dicarboxylato) ruthenium (II)) was purchased from Solaronix S.A, Switzerland.

\subsection{Sample preparation and composition}

Composite electrolytes consisting of independent organic (Triton X-100 or PEG 200) -inorganic (TMOS) subphase were prepared. The composition of the first electrolyte

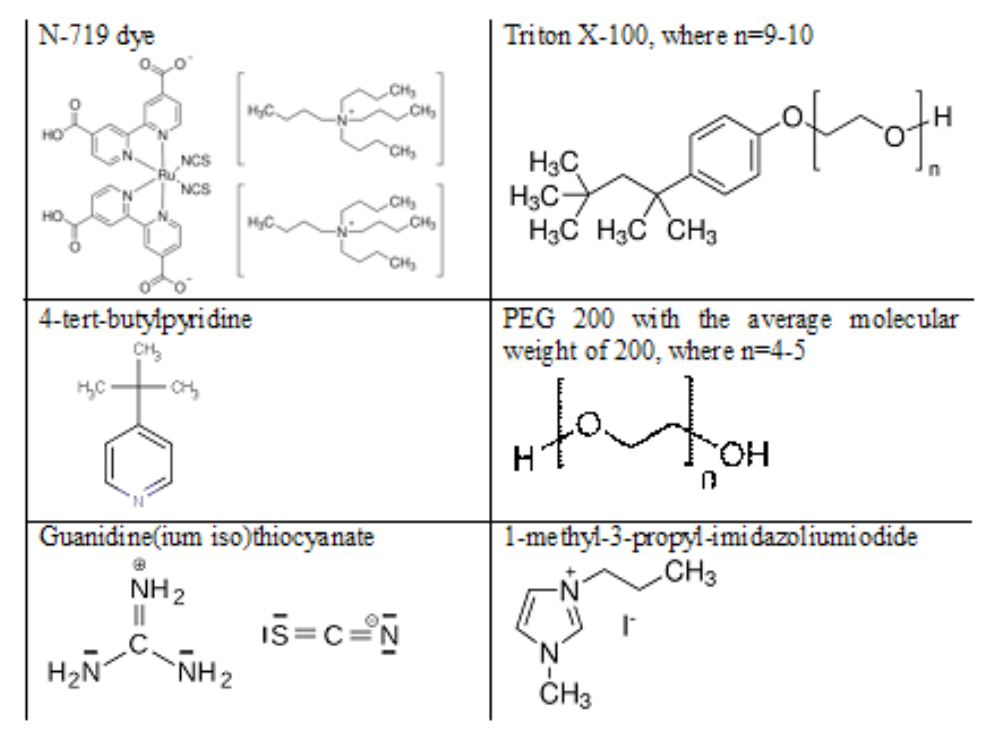

Scheme 1 Structural formula of a commonly used dye (N719) and some starting constituents of the electrolyte samples. 
abbreviated as S1 (0.85 M TMOS/0.29 M Triton X-100) is as follows: $0.85 \mathrm{M}$ tetramethoxysilane (TMOS), 4 drops hydrochloric acid $(\mathrm{HCl}), 0.29 \mathrm{M}$ Triton X-100, 0.5 M lithium iodide (LiI), 0.07M iodine ( $\left.\mathrm{I}_{2}\right), 0.5 \mathrm{M}$ 4-tert-butylpyridine (TBP), 0.2 M 1-methyl-3-propylimidazolium iodide (MPII) and $0.1 \mathrm{M}$ guanidinium thiocyanate diluted in acetonitrile (AcN). A second electrolyte (abbreviated as S2 (0.47 M TMOS/0.6 M PEG 200)) consisted of 0.47 M TMOS, 3 drops $\mathrm{HCl}$ (catalytic amount), $0.6 \mathrm{M}$ poly(ethylene glycol) 200 (PEG 200), 0.5 M LiI, 0.07 M I , 0.5 M TBP, $0.2 \mathrm{M}$ MPII and $0.1 \mathrm{M}$ guanidinium thiocyanate diluted in acetonitrile was also prepared. Moreover, the third sample S3 (0.31 M TMOS/0.6 M PEG 200) consisted of $0.31 \mathrm{M}$ TMOS, 2 drops $\mathrm{HCl}$ diluted in acetonitrile. Then $0.6 \mathrm{M}$ poly(ethylene glycol) 200 (PEG 200), 0.5 M LiI, 0.07 M I $0.5 \mathrm{M}$ TBP, $0.2 \mathrm{M}$ MPII, and $0.1 \mathrm{M}$ guanidinium thiocyanate were added with the as-mentioned row, whose overall composition is demonstrated in Table 1.

\subsection{In situ evolved gas analysis (EGA) by TG-FTIR}

A TGA 2050 Thermogravimetric Analyzer (TA Instruments, USA) with a heating rate of $10{ }^{\circ} \mathrm{C} \mathrm{min}^{-1}$, with air flow rate of $120 \mathrm{~mL} \mathrm{~min}^{-1}$ (and an extra $10 \mathrm{~mL} \mathrm{~min}^{-1}$ air as a balance purge), and sample size of $13-31 \mathrm{mg}$ in open Pt crucible were used. Gaseous species evolved from the sample were led into FTIR-gas cell of the BioRad TGA/IR Accessory Unit equipped with Peltier-cooled DTGS detector through a heated stainless steel transfer line $(1=90 \mathrm{~cm}, \operatorname{din}=2 \mathrm{~mm}) \mathrm{kept}$ at $\mathrm{T}=180{ }^{\circ} \mathrm{C}$. FTIR spectra $\left(500-4000 \mathrm{~cm}^{-1}\right)$ were collected in every $30 \mathrm{~s}$ after accumulation of 29 interferograms by a BioRad Excalibur Series FTS 3000 spectrometer using Win IR Pro 2.7 FTIR (BioRad) data collection and evaluation software.

Table 1 Starting composition of the samples prepared

\begin{tabular}{lcccccc}
\hline & \multicolumn{2}{c}{ S1 } & \multicolumn{2}{c}{ S2 } & \multicolumn{2}{c}{ S3 } \\
& mg & mmol & mg & mmol & mg & mmol \\
\hline TMOS & 528 & 3.5 & 300 & 2.0 & 200 & 1.3 \\
HCI & 4 drop & & 3 drop & & 2 drop & \\
AcN & 2400 & 58.5 & 2800 & 68.3 & 2800 & 68.3 \\
Triton X-100 & 780 & 1.2 & - & & - & \\
PEG 200 & - & & 500 & 2.5 & 500 & 2.5 \\
LiI & 274 & 2.0 & 281 & 2.1 & 261 & 1.9 \\
I & 72.8 & 0.3 & 74.6 & 0.3 & 74.6 & 0.3 \\
TBP & 277 & 2.1 & 284 & 2.1 & 284 & 2.1 \\
MPII & 206.7 & 0.8 & 211.8 & 0.8 & 211.8 & 0.8 \\
Gu-SCN & 48.8 & 0.4 & 49.6 & 0.4 & 49.4 & 0.4 \\
\hline
\end{tabular}

\subsection{In situ EGA by coupled TG/DTA-MS}

A simultaneous TG/DTA apparatus (STD 2960 Simultaneous DTA-TGA, TA Instruments Inc., USA), a heating rate of $10{ }^{\circ} \mathrm{C} \mathrm{min}^{-1}$, an air flow rate of $130 \mathrm{~mL} \mathrm{~min}^{-1}$, sample sizes between 6 and $13 \mathrm{mg}$, in open Pt crucible were applied. The mixture of gaseous species could reach the ThermoStar GDS 200 (Balzers Instruments) quadrupole mass spectrometer equipped with Chaneltron detector, through a heated $100 \%$ methyl deactivated fused silica capillary tubing kept at $\mathrm{T}=200{ }^{\circ} \mathrm{C}$. Data collection was carried out with QuadStar 422v7.02 software in scanning (SCAN) mode in the range of $\mathrm{m} / \mathrm{z}=1-300(0.2 \mathrm{~s} /$ channel, cycle time is ca. $60 \mathrm{~s}$ ) and also in Multiple Ion Detection (MID) mode monitoring only 64 selected channels based on changes observed in scanning mode. Measuring time was ca. $0.5 \mathrm{~s}$ for one channel, resulting in time of measuring of each MID cycle in ca. $38 \mathrm{~s}$.

\subsection{Identification and evolution rate curves of gaseous species}

Identification of the various released volatile components have been carried out based on reference IR and MS spectra of vapors and gases available mainly from NIST Chemistry Webbook [28] (basically EPA Vapor Phase Library) and vapor references collected in [33].

Evolution curves (release rate curves) of volatile components (solvent vapors and any gaseous decomposition products) have been constructed by plotting baseline corrected peak heights (absorbance) or area (integrated absorbance) of characteristic absorption bands and ion current of characteristic $\mathrm{m} / \mathrm{z}$ ions versus sample temperature in case of FT-IR and MS measurements, respectively. The appropriate characteristic bands and mass / charge $(\mathrm{m} / \mathrm{z})$ values were chosen carefully, in order to avoid any spectral interferences or overlapping, whenever that was possible.

By EGA-MS, the identification of the evolving components and degradation products, tracing occurrence and intensity of molecular and fragment ions of a gas molecule, were carried out in two steps in two different detection mode of the MS. In the first step we scanned the whole $\mathrm{m} / \mathrm{z}$ region between 1-300 $\mathrm{m} / \mathrm{z}$ (Scan mode), during the heating program of the TG and then from this spectra we selected the characteristic, changing $\mathrm{m} / \mathrm{z}$ values and carried out a more sensitive 64-channel following (MID mode) experiment. 


\section{Results and discussion}

\subsection{Comparative thermogravimetric analysis} (TG/DTG) of TMOS-based electrolyte samples incorporating either Triton X-100 or PEG 200

For all the three samples, we can separate at least three decomposition stages according to the TG and DTG curves, similarly to our previous experiments with UreaSil based electrolytes [19]. In the first main step, it can be assumed, that the most volatile, solvent-like components are evolved and then in the second main step the TMOS based gel matrix's decomposition occurred. The decomposition temperature of the gel matrix seems to be lowered for the samples with less TMOS content. While it started around $200^{\circ} \mathrm{C}$ for the highest TMOS containing S1 $(0.85 \mathrm{M}$ TMOS/0.29 M Triton X-100) sample, it lowered to $195^{\circ} \mathrm{C}$ for sample S2 (0.47 M TMOS/0.6 M PEG 200) and has been observed even lower, around $193{ }^{\circ} \mathrm{C}$ for sample S3 (0.31 M TMOS/0.6 M PEG 200) as seen on Fig. 1 [18]. The fine dynamical variations - observed on the DTG curves up to these temperatures - indicate already the release complexity of various volatile components studied by both FTIR and MS coupled EGA-methods. At the end of the heating program, some high temperature burning outs occurred, causing some further weight losses even above $500{ }^{\circ} \mathrm{C}$.

The overall homogeneity of samples together with reproducibility on the two thermal balances has been satisfactory, except in one case of sample S3 (Fig. 1(d) and (e)) which can be explained by the difference in packing density causing the volatile part to increase at the expense of the decomposition range.

\subsection{Identification of the volatile components and decomposition products by FTIR}

We had already given a preliminary comparison of these gel samples to those prepared on TMOS based in our previous work [18], using the absorption band of $\mathrm{CH}$ stretching vibrations, which - occurring between 2600 and $3100 \mathrm{~cm}^{-1}$ in the FTIR-gas spectra series - characterize the overall vapor release of organics. Here we present a more detailed analysis of these TMOS based electrolyte samples.

In the first stage, from all three samples little amount of methanol (followed at $1034 \mathrm{~cm}^{-1}$ characteristic peak) starts to evolve at the very beginning of the heating program (Fig. 2, first row). The evolved methanol's source is most
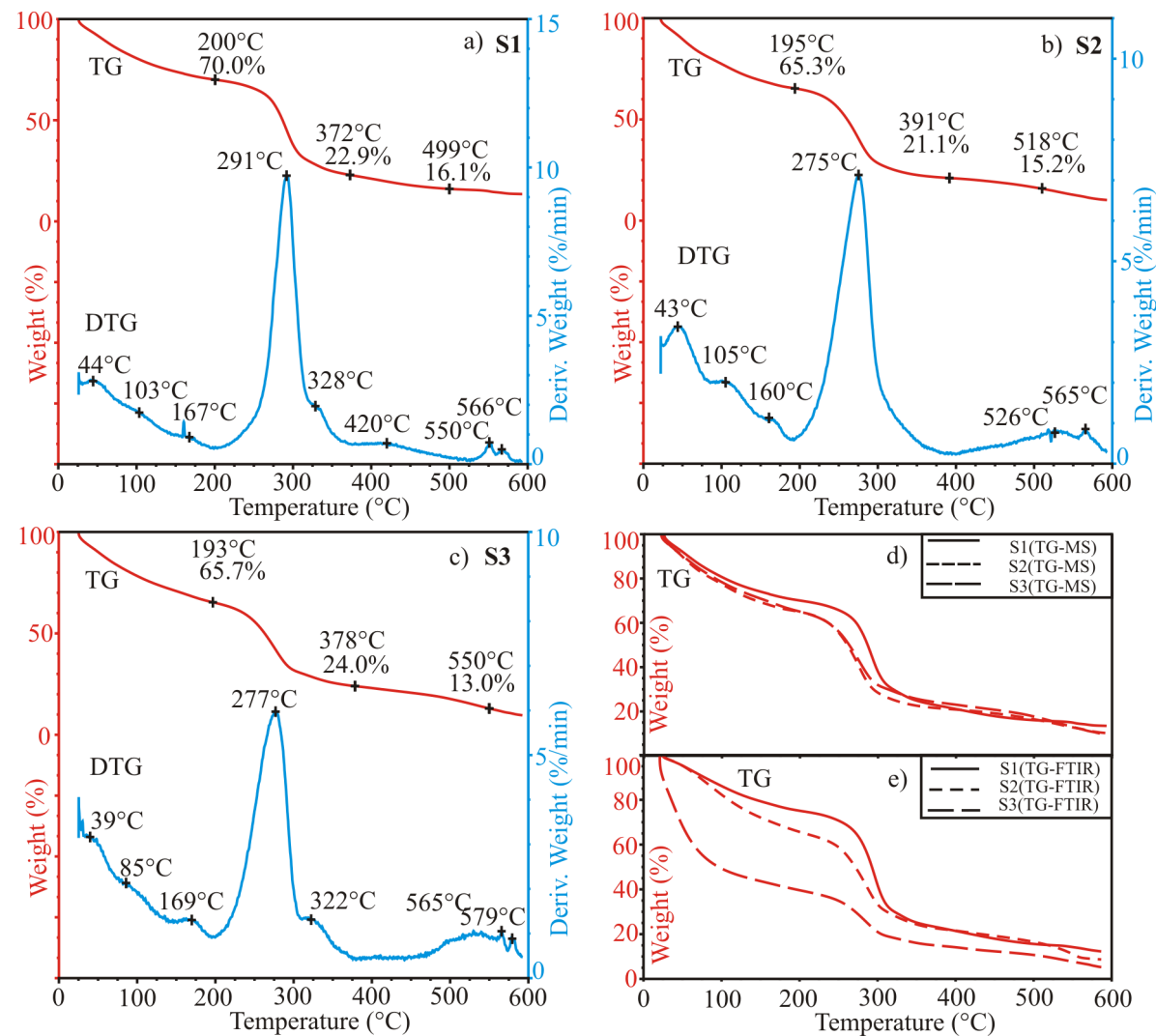

Fig. 1 TG/DTG curves (from EGA - MS - MID measurements) of the samples (a) S1 (0.85 M TMOS/0.29 M Triton X-100, 8.40 mg), (b) S2 (0.47 M TMOS/0.6 M PEG 200, $8.46 \mathrm{mg}$ ) and (c) S3 (0.31 M TMOS/0.6 M PEG 200, 6.39 mg) and their TG-curve comparisons from coupled MS and FTIR series of measurements, (d) and (e), respectively. 
S1
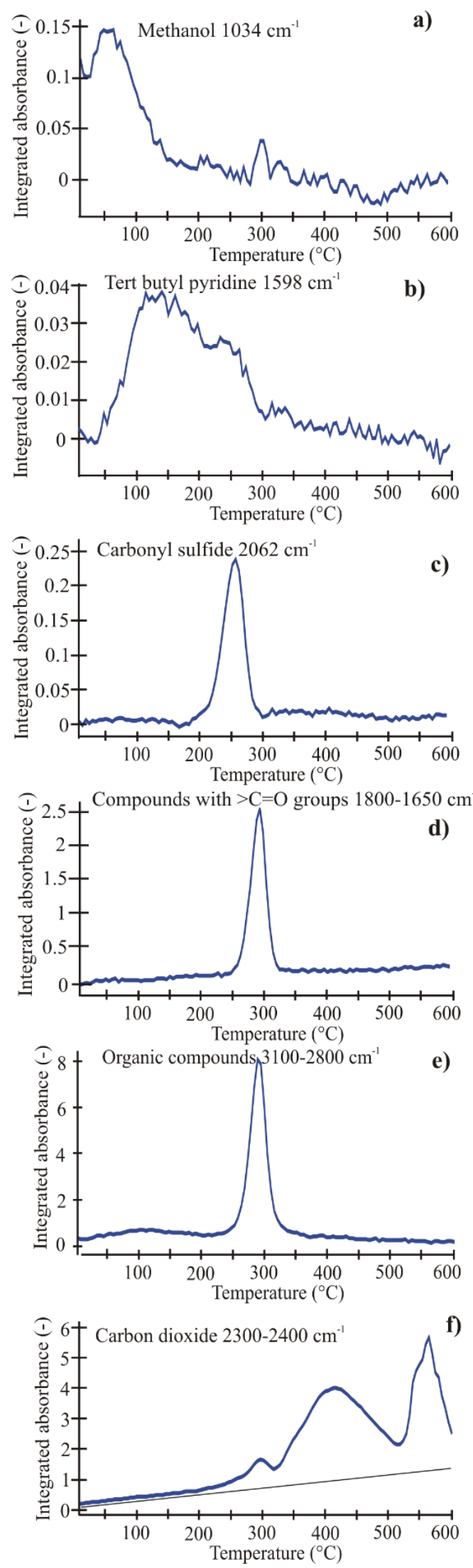

S2
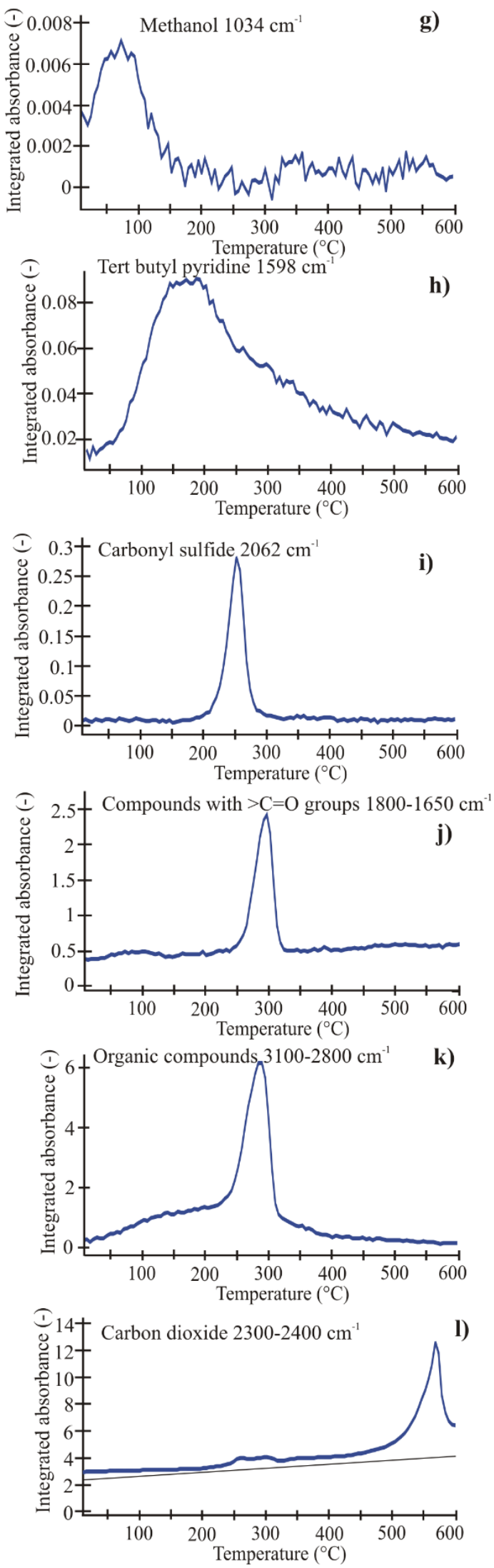

Fig. 2 The comparison of FTIR evolution rate curves of volatiles from sample S1 (0.85 M TMOS/0.29 M Triton X-100, left column) and S2 (0.47 M TMOS/0.6 M PEG 200, right column) in the TG - EGA - FTIR measurements (initial weight of $22.475 \mathrm{mg}$ and $31.503 \mathrm{mg}$, respectively). 
likely the TMOS-based matrix polycondensation process, which is still ongoing or its by-product's (i.e. MeOH's) release is delayed a bit and accelerated by the electrolyte TG-test. (Note: In the case of sample S3 we were also able to detect some acetonitrile evolving together with methanol, see Fig. 3. Although we were able to observe it only for this particular sample because of the very low amount evolving, it cannot be excluded, that it escapes from all three samples, but the detection limit by FTIR was not high enough to make it visible.)

Then, an elongated evolution of 4-tert-butylpyridine $\left(1598 \mathrm{~cm}^{-1}\right)$ was observed, which occurred in a wide temperature range, centered somewhere between 150 and $250{ }^{\circ} \mathrm{C}$. 4-tert-butylpyridine (bp. $196-197{ }^{\circ} \mathrm{C}$ [29-30]) is a known volatile additive component and it is leaving the electrolyte without decomposition in rather broad temperature range.

Surprisingly, some carbonyl sulfide (COS, $2062 \mathrm{~cm}^{-1}$ ) occurs also from around $200{ }^{\circ} \mathrm{C}$ as can be seen in third raw of Fig. 2. The carbonyl sulfide evolution seems to originate from the guanidinium thiocyanate additive, whose decomposition we decided to follow and study in details alone, as well, as it is one of the most important additives of a DSSC electrolyte, and the results will be presented later in this paper.

Above $300{ }^{\circ} \mathrm{C}$, from all three samples, probably mixtures of some oxidized compounds, all bearing various forms of carbonyl groups are released, most probably arising from oxidative degradation / depolymerization of oligo(ethylene glycolic) chains of Triton $\mathrm{X}-100(\mathrm{~S} 1, n=9-10)$ and PEG 200 (S2 and S3, $n=4-5)$. These are considered as decomposition products of the TMOS/oligo(ethyleneoxo) type gel matrices and indicate also the collapse of the matrix (Fig. 2, fourth and fifth rows) itself. That's why, thermal degradation of the TMOS-based matrix, in second large decomposition stage, can be demonstrated - in the best way - with $>\mathrm{C}=\mathrm{O}$ stretching absorption bands coming from various degradation products of radical thermolysis and partial oxidation of oligo(glycol) (side)chains [34] of gel deeply and strongly incorporating either PEG 200 or Triton X-100.

An overview of evolved products exhibits, that - after the used solvent acetonitrile, and formed polycondensation product, methanol (Fig. 3) - first the gel's enclosed additives, like 4-tert-butylpyridine, or degradation products of some additives, like COS from isothiocyanate salt are escaping before the matrix system collapses. The collapse can also be indicated - beyond the occurrence of the unidentified compounds with oxo-groups - by some small evolution rate of ammonia (not shown), most likely originated from somehow very strongly retarded / polycondensed guanidine, and also escaping in unpredictable ways.

Between 500-600 ${ }^{\circ} \mathrm{C}$ burning out of the gradually tarring and charring organic residues is the most probable process with exothermic heat effect, also escorted with evolution of $\mathrm{CO}_{2}$. Anyhow, in case of the sample $\mathrm{S} 1$, we can see that $\mathrm{CO}_{2}$ is evolving already from around $200{ }^{\circ} \mathrm{C}$, while only from $450{ }^{\circ} \mathrm{C}$ for $\mathrm{S} 2$ and $\mathrm{S} 3$. This can be explained with the given Triton $\mathrm{X}-100$ content of this sample specifically, as quite early $\mathrm{CO}_{2}$ evolution - as result of easy ignition tendency of isooctyl group - is observed for pure Triton X-100, as well [31]. Thus differences in the $\mathrm{CO}_{2}$ evolution curves of the samples $\mathrm{S} 1$ and $\mathrm{S} 2$, which shown in last raw of Fig. 2, are caused by compositional differences between S1 sample - containing Triton X-100 molecule (easy to ignite) - and S2 sample - containing PEG 200 - without tendency for ignition, instead.

At $600{ }^{\circ} \mathrm{C}$, after burning out of all the organic matters, we expected occurrence of some inorganic materials, like silica (in amorphous state) and crystalline LiI, anyhow the latter could not be observed, at all. Although crystalline LiI ought to melt at $469{ }^{\circ} \mathrm{C}$ and provide an endothermic heat effect, but before this, probably, it - as an C-O bond cleavage agent - reacted with organic matrix components and eliminated in form of various alkyl-iodides from our systems [18, 19]. In our previous studies when KI was used
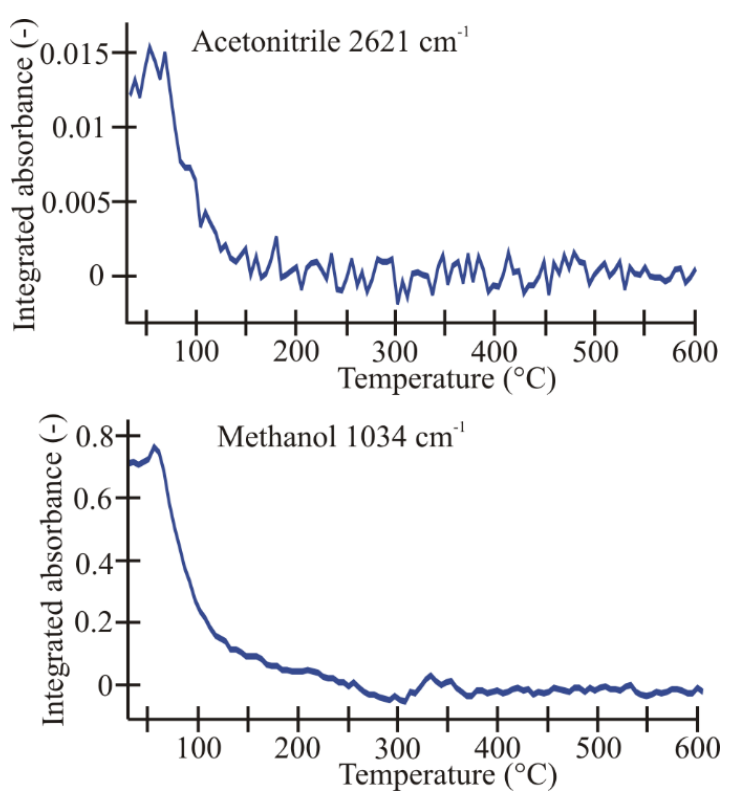

Fig. 3 The FTIR evolution curve of acetonitrile and methanol from sample S3 (0.31 M TMOS/0.6 M PEG 200). (TG - FTIR measurement, initial weight of $13.702 \mathrm{mg}$.) 
as electrolyte components instead of LiI, the powder X-ray diffraction measurement confirmed crystalline KI as final residue to be present [17], but in these cases with LiI, we couldn't observe any crystalline phase in the final residues.

The FTIR evolution curves of sample S3 are not shown here in full details because they are very similar to the evolution curves of sample S2, due to their similar composition. Although we have to mention that evolution of a small amount of acetonitrile was observed from this sample at the beginning of the measurement and also a lowering of the decomposition processes of sample S3 compared to $\mathrm{S} 2$ by around $5^{\circ} \mathrm{C}$ in accordance with their TG curves (Fig. 1).

\subsection{Identification of the evolving components and decomposition products by TG-MS in two detection modes (Scan \& MID)}

In the parallel EGA-MS measurements of all the three samples, we have been able to observe and identify a lot of evolved species even in MS-Scan mode, and also confirm and follow them in MS-MID mode, based on their molecular ion and/or characteristic ion fragments. Among them there are several species which had already been identified in our EGA-FTIR spectroscopic measurements, but some new
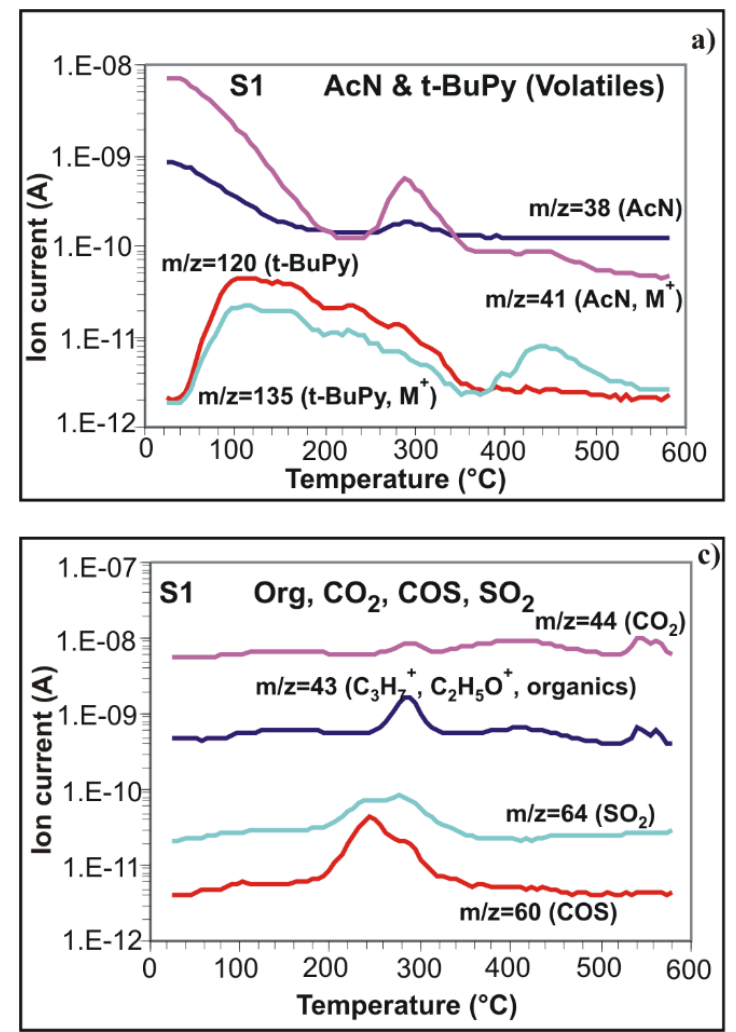

volatile species, like sulfur dioxide $\left(\mathrm{SO}_{2}, \mathrm{~m} / \mathrm{z}=64, \mathrm{M}^{+}\right)$, elemental iodine $\left(\mathrm{I}_{2}, \mathrm{~m} / \mathrm{z}=256, \mathrm{M}^{+}\right)$and two alkyl-iodides, such as methyl iodide $\left(\mathrm{MeI}, \mathrm{m} / \mathrm{z}=142, \mathrm{M}^{+}\right)$and propyl iodide $\left(\operatorname{PrI}, \mathrm{m} / \mathrm{z}=170, \mathrm{M}^{+}\right.$) were not visible in the FTIR spectra. In these cases, the used Q - MS, as a detector system seems to be more sensitive than our FTIRspectroscopic gas cell technique, especially for compounds containing sulfur and iodine atoms, so we could clearly see by MS even very small amount of some alkyl-iodides and oxidation product of sulfurous species evolving.

In MS-MID mode we have tried to follow all the identified components on several $\mathrm{m} / \mathrm{z}$ values to find the most characteristic ones and avoid any interference because of low resolution of the quadrupole spectrometer, as much as it was possible. In this way, we have been able to confirm and create one or more MS-evolution rate curve(s) for most of the components identified by FTIR. Unfortunately it was hardly successful for methanol $\left(\mathrm{m} / \mathrm{z}=32\left[\mathrm{M}^{+}\right]\right)$, because of bothering interferences of air-components, but it was very successful for acetonitrile $\left(\mathrm{m} / \mathrm{z}=41\left[\mathrm{M}^{+}\right], 39,38\right)$, and especially for 4-tert-butylpyridine $\left(\mathrm{m} / \mathrm{z}=135\left[\mathrm{M}^{+}\right]\right.$, 120, 92, 65, 51) (Figs. 4(a), and 5(a)). Ammonia was followed at $\mathrm{m} / \mathrm{z}=15\left(\mathrm{NH}^{+}\right)$, because of strong interference of water's $\mathrm{m} / \mathrm{z}=17\left(\mathrm{OH}^{+}\right)$fragment (Figs. 4(b) and 5(b)).
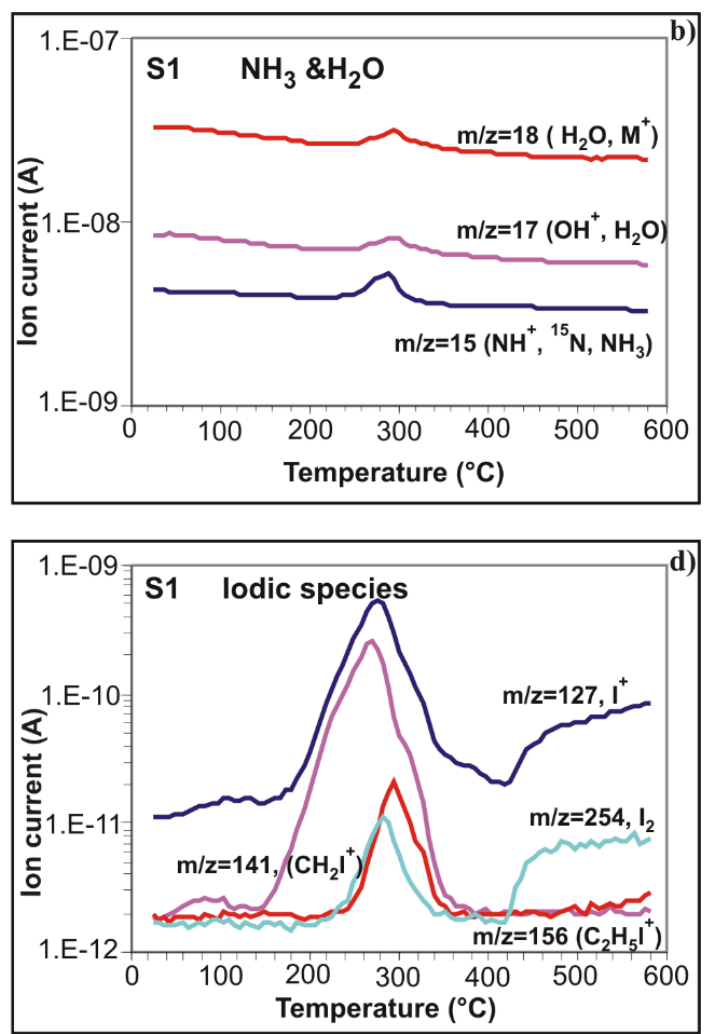

Fig. 4 MS evolution curves of released gaseous species from samples $\mathrm{S} 1$ (Triton X-100) (a) AcN \& 4-tert-Butylpyridine, (b) $\mathrm{H}_{2} \mathrm{O}$ \& $\mathrm{NH}_{3}$, (c) organics, $\mathrm{CO}_{2}, \mathrm{COS}$, and $\mathrm{SO}_{2}$ ), and (d) iodic species as obtained in TG/DTA - EGA - MS - MID (following) mode measurements. 

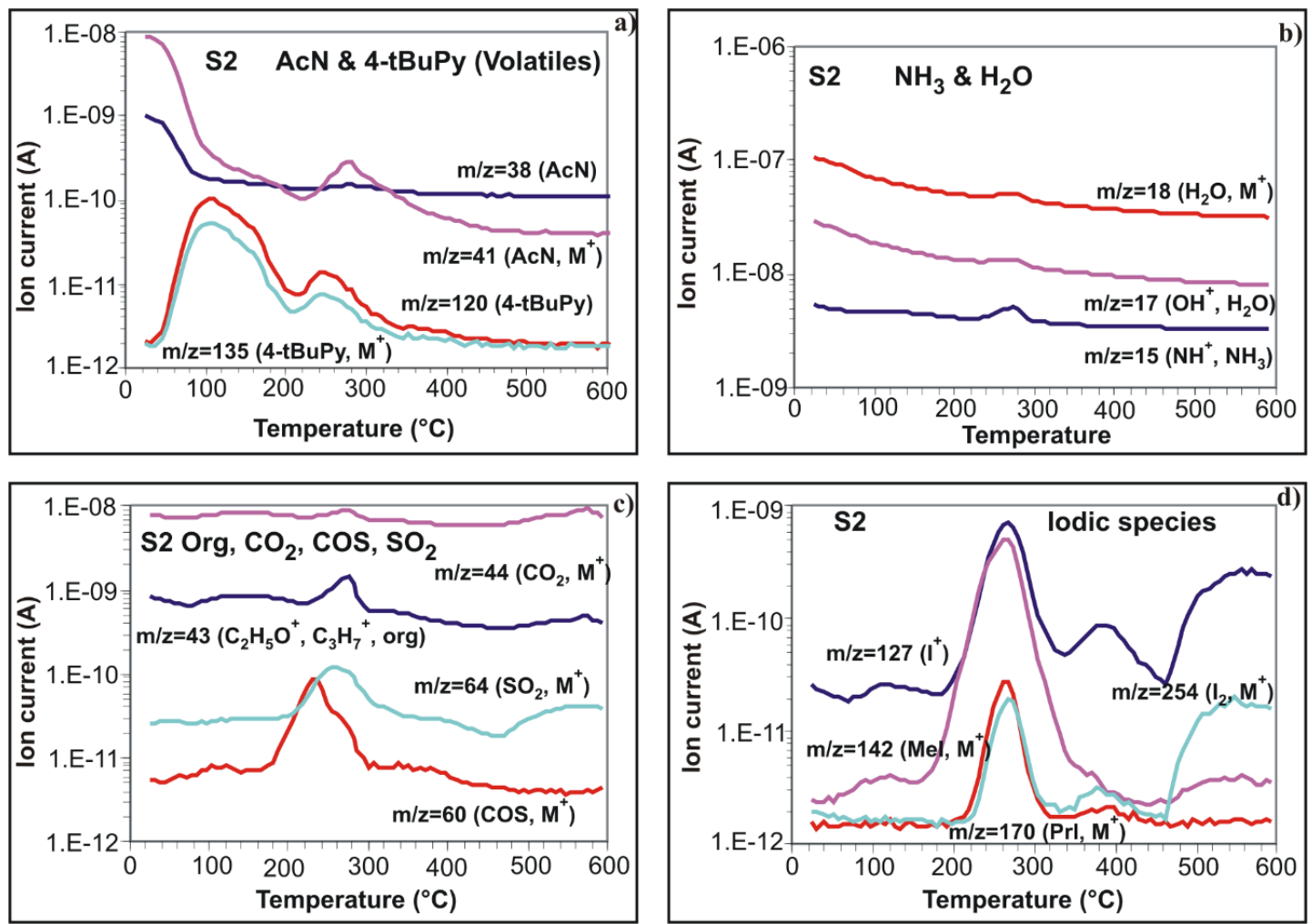

Fig. $5 \mathrm{MS}$ evolution curves of released gaseous species from samples $\mathrm{S} 2$ (PEG 200). (a) AcN \& 4-tert-Butylpyridine, (b) $\mathrm{H}_{2} \mathrm{O} \& \mathrm{NH}_{3}$, (c) organics, $\mathrm{CO}_{2}, \mathrm{COS}$, and $\mathrm{SO}_{2}$ ), and (d) iodic species as obtained in TG/DTA-EGA-MS-MID (following) mode measurements.

Figs. 4(c) and 5(c) exhibit definite evolution courses of carbonyl sulfide $\left(\mathrm{COS}, \mathrm{m} / \mathrm{z}=60\left[\mathrm{M}^{+}\right]\right)$, sulfur dioxide $\left(\mathrm{SO}_{2}\right.$, $\mathrm{m} / \mathrm{z}=64\left[\mathrm{M}^{+}\right]$and carbon dioxide $\left(\mathrm{CO}_{2}, \mathrm{~m} / \mathrm{z}=44,22\right)$. Beyond these simple oxidative decomposition products of electrolyte samples, the sophisticated organic degradation products of the poly(ethyleneoxide) skeletal groups could universally be followed as the $\mathrm{m} / \mathrm{z}=43$ ions, presumably as $\left[\mathrm{C}_{3} \mathrm{H}_{7}^{+}\right]$or $\left[\mathrm{C}_{2} \mathrm{H}_{5} \mathrm{O}^{+}\right]$ionfragments coming from some unidentified volatile species derived from them.

Evolution of ionfragments of alkyl iodides with short alkyl chain, presumably methyl and propyl iodides $\left(\mathrm{m} / \mathrm{z}=142\left[\mathrm{MeI}^{+}\right], 170\left[\mathrm{PrI}^{+}\right]\right)$and molecules of iodine $\left(\mathrm{m} / \mathrm{z}=254\left[\mathrm{I}_{2}^{+}\right]\right)$could be detected only by EGA-MS (Figs. 4(d) and 5(d)). The course $\mathrm{m} / \mathrm{z}=127\left(\left[\mathrm{I}^{+}\right]\right)$can be considered as a kind of specially combined evolution rate of "overall iodic species", for all the three species containing iodine atoms, mentioned. Based on our previous study [19] we can also suggest that both methyl and propyl iodides are degradation or reaction products of one of hereto also applied additives, 1-methyl-3-propylimidazolium iodide (MPII). The origin of evolution of water at high temperature $\left(\sim 250^{\circ} \mathrm{C}\right)$ is probably the inflamed vapors in air atmosphere.
Carbonyl sulfide and ammonia are suspected degradation products of another important additive, guanidinium thiocyanate, whose decomposition we studied in details, as described in Subsection 3.4.

\subsection{Thermal study of pure guanidinium thiocyanate, one of the highly important electrolyte additives}

The TG, DTG, and DTA curves of guanidinium thiocyanate salt are presented in Fig. 6. The temperature of its endothermic melting is well observable at $121.6{ }^{\circ} \mathrm{C}$ what concur with the melting points in the literature $\left(118-122^{\circ} \mathrm{C}\right.$, [32]). (Interesting to note, that the thermal balance detects also some "spikes in weight changes", which are escorting the fusion of the nicely grown crystals into molten salt, probably because of differences in the apparent density of the crystal mass and the melt or can be a sign of some captured gas / solvent lost upon melting.) The melt of the salt looks stabile till around $230{ }^{\circ} \mathrm{C}$ when a decomposition starts with an intensive mass loss, while the weight seems to be stabilized between 330 and $390^{\circ} \mathrm{C}$, again at a ca. $39 \%$ level. Nevertheless, at around $410{ }^{\circ} \mathrm{C}$, there is again a small jump (6\%) in the weight, while at higher temperature, starting from $450{ }^{\circ} \mathrm{C}$ the decomposition is 


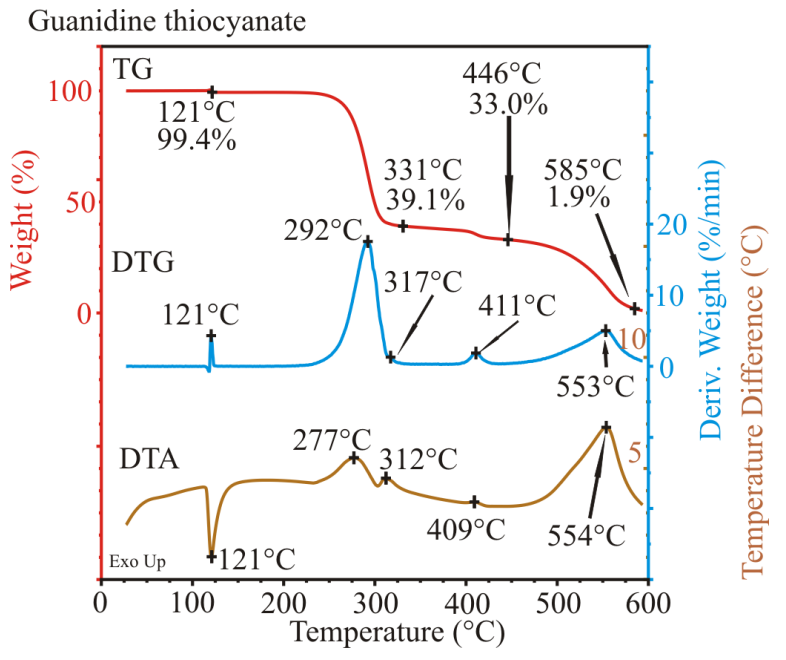

Fig. 6 The thermal analysis curves (TG/DTG/DTA) of guanidinium thiocyanate (initial weight $10.084 \mathrm{mg}$ ), of one of the most important electrolyte additives for DSSC, show a well-defined melting at $121.6^{\circ} \mathrm{C}$ and exothermic decomposition(s) from $250^{\circ} \mathrm{C}$ and burning after $450{ }^{\circ} \mathrm{C}$.

still continuing with a slow burning out of tarring / charring residues, in air.

\subsubsection{Identification of the decomposition products of guanidinium thiocyanate by TG-FTIR}

We have also carried out a detailed evolved gas analyses of pure guanidinium thiocyanate, identifying the evolved gas components according to their FTIR and MS spectra with the help of references. In FTIR spectra of the gaseous mixtures released, we were able to identify various reaction products of the guanidinium and the thiocyanate part of the molecule, and their burning products, very similar species to those of identified formerly in case of decomposition of thiourea [33].

The identified components of evolved gaseous mixtures helped us to follow and interpret in more detailed way the decomposition processes which are observed from the TG / DTG / DTA curves. Before the massive mass loss, during melting, we haven't detected any evolving gases, nevertheless starting at around $250{ }^{\circ} \mathrm{C}$ (also observed from the TG curves) various volatile products were identified. First isothiocyanic acid, HNCS seems to occur, most likely arising from a dissociative decomposition process of the title compound, namely decomposition into its neutral constituents, guanidine base and volatile isothiocyanic acid (Eq. (1)), as a result of migration of a proton.

$$
\begin{aligned}
& {\left[\left(\mathrm{NH}_{2}\right)_{2} \mathrm{C}=\mathrm{NH}_{2}\right]^{+} \cdot \mathrm{NCS}_{(1)}^{-}} \\
& =\left(\mathrm{NH}_{2}\right)_{2} \mathrm{C}=\mathrm{NH}_{(1)}+\mathrm{HNCS}_{(1, \mathrm{~g})} .
\end{aligned}
$$

At this temperature the isothiocyanic acid seems to be sensitive to oxidation, so simultaneous occurrence of hydrogen cyanide $(\mathrm{HCN})$ and sulfur dioxide gases are considered to be its oxidation products in the air (Eq. (2)).

$\mathrm{HNCS}_{(\mathrm{g})}+\mathrm{O}_{2(\mathrm{~g})}=\mathrm{HCN}_{(\mathrm{g})}+\mathrm{SO}_{2(\mathrm{~g})}$.

Formation of ammonia gas and cyanamide, $\mathrm{NH}_{2} \mathrm{CN}$ vapor is coming from the probably from a partial degradation of guanidine (Eq. (3)), a product formed in the first reaction (Eq. (1)).

$\left(\mathrm{NH}_{2}\right)_{2} \mathrm{C}=\mathrm{NH}_{(1)}=\mathrm{NH}_{2} \mathrm{CN}_{(1, \mathrm{~g})}+\mathrm{NH}_{3(\mathrm{~g})}$.

An intense evolution of carbon disulfide, $\mathrm{CS}_{2}$ (also together with cyanamide, $\mathrm{NH}_{2} \mathrm{CN}$ ) may come from reaction between two thiocyanic acid molecules (Eq. (4)) in the condensed phase.

$2 \mathrm{HNCS}_{(1)} \Leftrightarrow \mathrm{NH}_{2} \mathrm{CN}_{(1, \mathrm{~g})}+\mathrm{CS}_{2(\mathrm{~g})}$.

Meanwhile, the simultaneous formation of carbonyl sulfide (COS) and sulfur dioxide $\left(\mathrm{SO}_{2}\right)$ indicates an immediate quick oxidation process (a mild explosion) of carbon disulfide vapors evolved from the sample (Eq.(5)).

$$
\mathrm{CS}_{2(\mathrm{~g})}+1.5 \mathrm{O}_{2(\mathrm{~g})} \Leftrightarrow \mathrm{COS}_{(\mathrm{g})}+\mathrm{SO}_{2(\mathrm{~g})} \text {. }
$$

At $410{ }^{\circ} \mathrm{C}$ an additional peak is visible in all the component's evolution curves (except that of HNCS), what we also observed at the DTG curve. It could be caused by further decomposition of the tarring residuals of sample, when the inner part of the sample is produced a new step of decomposition, which happen at higher temperature, $410{ }^{\circ} \mathrm{C}$. Finally, at high temperature, above $500{ }^{\circ} \mathrm{C}$, carbon dioxide and dinitrogen oxide evolved from the sample as burning out products of final carbonaceous residues of guanidinium thiocyanate sample.

Interestingly, when following the decomposition of the electrolytes containing guanidinium thiocyanate, the single identified decomposition product of the guanidinium thiocyanate in the gas mixture was carbonyl sulfide alone, despite some other products were also expected to evolve in the same or bit higher amount from the pure material. This let us suggest that in the electrolyte mixture the decomposition occurs probably differently or the presence of other gases promote some alternative high temperature reactions with the decomposition products of the guanidinium thiocyanate content. 

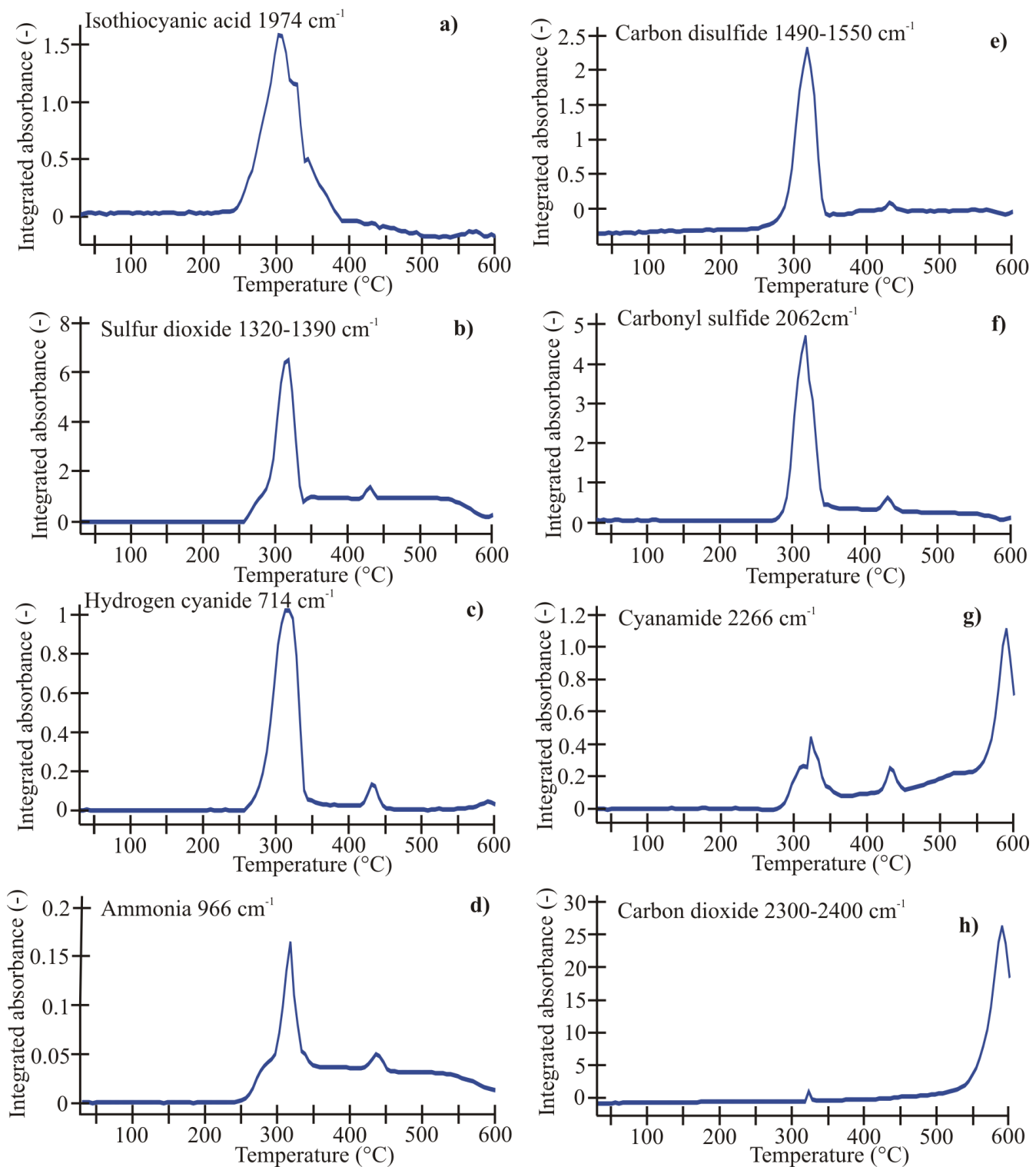

Fig. 7 FTIR spectroscopic evolution curves of gases coming from pure guanidinium thiocyanate, as one of the most important electrolyte additives for DSSC by TG-FTIR measurement with the initial weight of $25.265 \mathrm{mg}$.

\subsubsection{Identification of the decomposition products of guanidinium thiocyanate by TG/DTA-MS}

For the identification of the evolving components and degradation products, we used the same technique what we used for the electrolyte samples.

We have tried to follow the possible components on several characteristic $\mathrm{m} / \mathrm{z}$ value and to avoid interferences of the quadrupole spectrometer as much as possible, and to confirm several components identified by FTIR, such as carbon disulfide $\left(\mathrm{CS}_{2} \mathrm{~m} / \mathrm{z}=76\right)$, sulfur dioxide $(\mathrm{m} / \mathrm{z}=64)$, ammonia $(\mathrm{m} / \mathrm{z}=15)$, carbonyl sulfide $(\mathrm{m} / \mathrm{z}=60)$, cyanamide $(\mathrm{m} / \mathrm{z}=42)$, and carbon dioxide $(\mathrm{m} / \mathrm{z}=44,22)$. Unfortunately, because of strong fragmentations and interferences we couldn't confirm hydrogen cyanide, (iso) thiocyanic acid or dinitrogen oxide, although they were followed by FTIR.

\section{Conclusions}

Our parallel TG measurement showed good reproducibility and homogeneity for samples S1 (0.85 M TMOS/0.29 M Triton X-100) and S2 (0.47 M TMOS/0.6 M PEG 200) while a considerable inhomogeneity was observed in case of sample S3 (0.31 M TMOS/0.6 M PEG 200). We were able to separate at least three decomposition steps for all three samples where in the first main step the volatile, solvent-like components evolved and then in the second main 
step the decomposition of the TMOS based gel matrices occurred. From the TG/DTG curves we observed that with less TMOS content the decomposition temperature of the gel matrix lowered therefor the sample S1 $(0.85 \mathrm{M}$ TMOS/0.29 M Triton X-100) showed the highest decomposition temperature and $\mathrm{S} 3(0.31 \mathrm{M}$ TMOS/0.6 M PEG 200) showed the lowest, ranging from $200{ }^{\circ} \mathrm{C}$ to $195{ }^{\circ} \mathrm{C}$ to $193{ }^{\circ} \mathrm{C}$ with the lowering TMOS content.

For the identification of the released gases and decomposition products we used complimentary and confirming feature of FTIR and MS online coupled with a TG furnace. From all three samples with the FTIR gas cell we identified methanol and evolving from the beginning of the measurement and for sample S3 we were also able to detect acetonitrile evolving together with methanol in a very low amount, what makes it possible, that it escaped from all three samples, but we were not able to detect it. It was followed by 4-tert butylpyridine and carbonyl sulfide evolution from around $200{ }^{\circ} \mathrm{C}$. The known component, 4-tert butylpyridine was leaving the electrolyte without decomposition. The carbonyl sulfide originates from the guanidine thiocyanate according to our detailed studies on this additive.

Above $300{ }^{\circ} \mathrm{C}$ from all three samples ammonia starts to evolve, what is considered to evolve from the guanidine residue of the additive guanidinium thiocyanate. Between 500-600 ${ }^{\circ} \mathrm{C}$ burning out of organic residues was escorted with $\mathrm{CO}_{2}$ evolution for all the samples but the evolution dynamics was highly depending on the composition of the sample. Especially, in the case of use of Triton X-100 (S1) the carbon dioxide evolution occurred earlier in several steps, elongated between $250-600{ }^{\circ} \mathrm{C}$ while in the case of samples containing PEG 200 (S2 and S3) the carbon dioxide evolved in one step only above $450{ }^{\circ} \mathrm{C}$.

\section{References}

[1] O' Reagen, B., Grätzel, M. "A Low-Cost High-Efficiency Solar Cell Based on Dye-Sensitized Colloidal $\mathrm{TiO}_{2}$ Films", Nature, 353, pp. 737-740, 1991. http://doi.org/10.1038/353737a0

[2] O' Regan, B. C., Durrant, J. R. "Kinetic and Energetic Paradigms for Dye-Sensitized Solar Cells: Moving from the Ideal to the Real", Accounts of Chemical Research, 42(11), pp. 1799-1808, 2009. https://doi.org/10.1021/ar900145z

[3] Leite, E. R. "Nanostructured Materials for Electrochemical Energy Production and Storage", Series: Nanostructure Science and Technology, Springer-Verlag, New York, USA, 2009.

[4] Pan, X., Wang, M., Fang, X., Zhang, C., Huo, Z., Dai, S. "Ionic liquid crystal-based electrolyte with enhanced charge transport for dye-sensitized solar cells", Science China Chemistry, 56(10), pp. 1463-1469, 2013.

https://doi.org/10.1007/s11426-013-4904-y
With MS detector beside the ones identified by FTIR we were able to follow various methyl and propyl iodides $(\mathrm{m} / \mathrm{z}=142,170)$, iodine and overall iodic content $(\mathrm{m} / \mathrm{z}=127)$ coming from MPII, sulphur dioxide $(\mathrm{m} / \mathrm{z}=64)$, carbonyl sulphide (COS) and with this more sensitive detector we were able to follow acetonitrile $(\mathrm{m} / \mathrm{z}=41,39,38)$, while at $\mathrm{m} / \mathrm{z}=43$ poly(ethyleneoxide) degradation groups were followed in both Scan and MID mode.

We also studied in details one of the most important additives, guanidinium thiocyanate, which after melting at $121.6{ }^{\circ} \mathrm{C}$, looks stabile until $250{ }^{\circ} \mathrm{C}$, when the decomposition starts with an intensive mass loss, during which we identified several components, such as isothiocyanic acid, hydrogen cyanide, and sulfur dioxide, carbon disulfide, ammonia, and carbonyl sulfide. In the later stage cyanamide, dinitrogen oxide and carbon dioxide evolved. At higher temperature, between 400 and $550{ }^{\circ} \mathrm{C}$ the decomposition is continuing and a final burning out step occurs.

We found it interesting, that although we identified several components, with similar intensity from pure guanidinium thiocyanate, we were only able to find only carbonyl sulfide and ammonia in the evolving gas mixture of the electrolytic samples. Because of this, we can assume that several alternative reactions are occurring among the electrolyte components during the decomposition process.

\section{Acknowledgements}

Intergovernmental bilateral financial support of researchers exchange within the Framework of the Agreement on the Scientific and Technological Cooperation between the Hungary and Hellenic Republic (Grant Nos. TéT_101-2011-0551, Hungary and No.29 TARGET REGION 1, Greece) is gratefully acknowledged.

[5] Lenzmann, F. O., Kroon, J. M. "Recent Advances in DyeSensitized Solar Cells", Advances in OptoElectronics, 2007, pp. 1-10, 2007. http://doi.org/10.1155/2007/65073

[6] Zhang, J., Häggman, L., Jouini, M., Jarboui, A., Boschloo, G., Vlachopoulos, N., Hagfeldt, A. "Solid-State Dye-Sensitized Solar Cells Based on Poly(3,4-ethylenedioxypyrrole) and MetalFree Organic Dyes", ChemPhysChem A European Journal of Chemical Physics and Physical Chemistry, 15(6), pp. 1043-1047, 2014.

https://doi.org/10.1002/cphc.201301075

[7] Lee, S., Jeon, Y., Lim, Y., Hossain, M. A., Lee, S., Cho, Y., Ju, H., Kim, W. "A new siloxane containing imidazolium iodide as electrolyte for dye-sensitized solar cell", Electrochimica Acta, 107, pp. 675-680, 2013.

https://doi.org/10.1016/j.electacta.2013.04.108 
[8] Huang, Y., Xiang, W., Zhou, X., Fang, S., Lin, Y. "The effect of oligo-organosiloxane on poly(ethylene oxide) electrolyte system for solid dye sensitized solar cells", Electrochimica Acta, 89, pp. 29-34, 2013.

https://doi.org/10.1016/j.electacta.2012.11.009

[9] Orel, B., Šurca Vuk, A., Ješe, R., Lianos, P., Stathatos, E., Judeinstein, P., Colomban, P. "Development of sol-gel redox $\mathrm{I}_{3}^{-} / \mathrm{I}^{-}$ electrolytes and their application in hybrid electrochromic device", Solid State Ionics, 165(1-4), pp. 235-246, 2003.

https://doi.org/10.1016/j.ssi.2003.08.037

[10] Venkatesan, S., Obadja, N., Chang, T.-W., Chen, L.-T., Lee, Y.-L. "Performance improvement of gel- and solid-state dye-sensitized solar cells by utilization the blending effect of poly (vinylidene fluoride-co-hexafluropropylene) and poly (acrylonitrile-co-vinyl acetate) co-polymers", Journal of Power Sources, 268, pp. 77-81, 2014. https://doi.org/10.1016/j.jpowsour.2014.06.016

[11] Tao, L., Huo, Z., Dai, S., Zhu, J., Zhang, C., Huang, Y., Zhang, B., Yao, J. "Stable quasi-solid-state dye-sensitized solar cell using a diamide derivative as low molecular mass organogelator", Journal of Power Sources, 262, pp. 444-450, 2014.

https://doi.org/10.1016/j.jpowsour.2014.03.128

[12] Li, Q., Tang, Q., Chen, H., Xu, H., Qin, Y., He, B., Liu, Z., Jin, S., Chu, L. "Quasi-solid-state dye-sensitized solar cells from hydrophobic poly(hydroxyethyl methacrilate/glycerin)/polyaniline gel electrolyte", Materials Chemistry and Physics, 144(3), pp. 287 $292,2014$.

https://doi.org/10.1016/j.matchemphys.2013.12.032

[13] Stathatos, E., Lianos, P., Lavrencic-Stangar, U., Orel, B. "A HighPerformance Solid-State Dye-Sensitized Photoelectrochemical Cell Employing a Nanocomposite Gel Electrolyte Made by the Sol-Gel Route", Advanced Materials, 14(5), pp. 354-357, 2002. https://doi.org/10.1002/1521-4095(20020304)14:5<354::AIDADMA354>3.0.CO;2-1

[14] Lianos, P. "Use of Time-Resolved Fluorescence Analysis to Assess Molecular Mobility and Ionic Conductivity in Nanocomposite Organic-Inorganic Gels", Journal of Fluorescence, 14(1), pp. 11-15, 2004.

https://doi.org/10.1023/B:JOFL.0000014654.29641.66

[15] Stergiopoulos, T., Arabatzis, I. M., Katsaros, G., Falaras, P. "Binary Polyethylene Oxide/Titania Solid-State Redox Electrolyte for Highly Efficient Nanocrystalline $\mathrm{TiO}_{2}$ Photoelectrochemical Cells", Nano Letters, 2(11), pp. 1259-1261, 2002. https://doi.org/10.1021/n1025798u

[16] Stathatos, E., Lianos, P., Surca Vuk, A., Orel, B. "Optimization of a Quasi-Solid-State Dye-Sensitized Photoelectrochemical Solar Cell Employing a Ureasil/Sulfolane Gel Electrolyte", Advanced Functional Materials, 14(1), pp. 45-48, 2004. https://doi.org/10.1002/adfm.200304479

[17] Madarász, J., Nagygyörgy, V., Stathatos, E., Pokol, G. "Ageing and thermal stability studies on quasi-solid composite electrolytes for Grätzel-type solar cells", Journal of Thermal Analysis and Calorimetry, 113(3), pp. 1055-1062, 2013. https://doi.org/10.1007/s10973-012-2904-3
[18] Apostolopoulou, A., Nagygyörgy, V., Madarász, J., Stathatos, E., Pokol, G. "Thermal stability and electrical studies on hybrid and composite sol-gel quasi-solid-state electrolytes for dye-sensitized solar cells", Journal of Thermal Analysis and Calorimetry, 121(1), pp. 371-380, 2015.

https://doi.org/10.1007/s10973-015-4556-6

[19] Nagygyörgy, V., Stathatos, E., Pokol, G., Madarász, J. "Thermoanalytical studies on ureasil-type gels filled with electrolytes containing 1-methyl-3-propylimidazolium iodide for quasi-solid-state dye-sensitized solar cells by TG and coupled methods of evolved gas analysis", Thermochimica Acta, 651, pp. 11-21, 2017. https://doi.org/10.1016/j.tca.2017.02.009

[20] Xia, J., Li, F., Huang, C., Zhai, J., Jiang, L. "Improved stability quasi-solid-state dye-sensitized solar cell based on polyether framework gel electrolytes", Solar Energy Materials and Solar Cells, 90(7-8), pp. 944-952, 2006.

https://doi.org/10.1016/j.solmat.2005.05.021

[21] Wang, P., Zakeeruddin, S. M., Comte, P., Exnar, I., Grätzel, M. "Gelation of Ionic Liquid-Based Electrolytes with Silica Nanoparticles for Quasi-Solid-State Dye-Sensitized Solar Cells", Journal of the American Chemical Society, 125(5), pp. 1166-1167, 2003. https://doi.org/10.1021/ja029294

[22] Grätzel, M. "Conversion of sunlight to electric power by nanocrystalline dye-sensitized solar cells", Journal of Photochemistry and Photobiology A: Chemistry, 164(1-3), pp. 3-14, 2004. https://doi.org/10.1016/j.jphotochem.2004.02.023

[23] Wang, Z.-S., Hara, K., Dan-oh, Y., Kasada, C., Shinpo, A., Suga, S., Arakawa, H., Sugihara, H. "Photophysical and (Photo) electrochemical Properties of a Coumarin Dye", The Journal of Physical Chemistry B, 109(9), pp. 3907-3914, 2005. https://doi.org/10.1021/jp044851v

[24] Lee, K.-M., Suryanarayanan, V., Ho, K.-C., Thomas, K. R. J., Lin, J. T. "Effects of co-adsorbate and additive on the performance of dye-sensitized solar cells: A photophysical study", Solar Energy Materials and Solar Cells, 91(15-16), pp. 1426-1431, 2007.

https://doi.org/10.1016/j.solmat.2007.03.009

[25] Grätzel, M. "Dye-sensitized solar cells", Journal of Photochemistry and Photobiology C: Photochemistry Reviews, 4(2), pp. 145-153, 2003. https://doi.org/10.1016/S1389-5567(03)00026-1

[26] Grätzel, M. "Photovoltaic performance and long term stability of dye-sensitized mesoscopic solar cells", Comptes Rendus Chimie, 9(5-6), pp. 578-583, 2006.

[27] Lund, T., Nguyen, P. T., Tran, H. M., Pechy, P., Zakeeruddin, S. M., Grätzel, M. "Thermal stability of the DSC ruthenium dye C106 in robust electrolytes", Solar Energy, 110, pp. 96-104, 2014. https://doi.org/10.1016/j.solener.2014.09.007

[28] National Institute of Standards and Technology (NIST) "NIST Chemistry WebBook, NIST Standard Reference Database Number 69", [online] Available at: http://webbook.nist.gov/chemistry/ [Accessed: 01 June 2018] 
[29] American Chemical Society "SciFinder, a Chemical Abstract Service Solution", [online] Available at: https://scifinder.cas.org [Accessed: 01 June 2018]

[30] Sigma-Aldrich Fine Chemical Company, [online] Available at: http://www.sigmaaldrich.com [Accessed: 01 June 2018]

[31] Madarász, J., Okuya, M., Varga, P. P., Kaneko, S., Pokol, Gy. "TG/DTA-EGA-MS studies on titania precursors with low content of organics for porous thin films of $\mathrm{TiO}_{2}$ ", Journal of Analytical and Applied Pyrolysis, 79(1-2), pp. 479-483, 2007. https://doi.org/10.1016/j.jaap.2006.12.026

[32] ChemSpider, Search and Share Company "Guanidine thiocyanate", [online] Available at: http://www.chemspider.com/ChemicalStructure.58557.html [Accessed: 01 June 2018]
[33] Madarász, J., Pokol, G. "Comparative evolved gas analyses on thermal degradation of thiourea by coupled TG-FTIR and TG/DTA-MS instruments", Journal of Thermal Analysis and Calorimetry, 88(2), pp. 329-336, 2007. https://doi.org/10.1007/s10973-006-8058-4

[34] Gallet, G., Erlandsson, B., Albertsson, A.-C., Karlsson, S. "Thermal oxidation of poly(ethylene oxide-propylene oxide-ethylene oxide) triblock copolymer: focus on low molecular weight degradation products", Polymer Degradation and Stability, 77(1), pp. 55-66, 2002.

https://doi.org/10.1016/S0141-3910(02)00079-4 